\title{
Mobile Inquiry-as-Play in Mathematics Teacher Education
}

Correspondence concerning this manuscript should be addressed to:

\author{
Jeremiah I. Holden \\ Assistant Professor, Information and Learning Technologies \\ School of Education and Human Development \\ University of Colorado Denver \\ 1380 Lawrence St., Room 645 \\ Denver, CO 80204 \\ remi.holden@ucdenver.edu \\ Office: (303) 315-0034
}

\begin{abstract}
This study describes the feasibility of designing and fostering pre-service teacher inquiry at the intersection of community and disciplinary engagement. Mapping My Math (MMM), a gamebased and mobile learning activity, guided pre-service teachers in playfully exploring mathematics featured in the everyday activities of people and places, and creatively representing this inquiry with digital media. This study draws from design-based research that examined the role of place, digital media, and mobility in mathematics teacher education. Design narrative methods describe how MMM was created, implemented, and refined to support disciplinary inquiry across settings given the evolution of tools, activities, and practices. The study and design narrative address the following question: How can game-based and mobile learning be designed to support pre-service teachers' disciplinary inquiry of everyday mathematics? Findings shared in this study's design narrative attend to the quality of pre-service teachers' inquiry-as-play, or expressive mobility situated amongst learners' social and material relations, disciplinary concepts, and the built environment. Implications from this study concern: the role of mobile learning in mathematics teacher education to connect school, community, and online settings; the potential of gameful design to impact pre-service teacher learning across settings; and the importance of fostering disciplinary inquiry whereby pre-service teachers can "navigate" their own learning. Game-based and mobile learning designs, like MMM, can create the conditions for cross-setting mobility as generative of inquiry-as-play in mathematics teacher education. MMM encouraged pre-service teachers to playfully leverage disciplinary practices that shaped new relationships with mathematics, their city, and the mathematics of place and community.

\section{Author Bio}

Jeremiah Holden is a teacher educator and learning scientist whose interests and design-based research concerns learning across settings, educators' design of games, and mobile learning. As Assistant Professor of Information and Learning Technologies at the University of Colorado Denver School of Education and Human Development, Jeremiah is a Creative Research Collaborative Fellow and also a member of the University of Colorado's President's Teaching and Learning Collaborative. His current research examines research-practice partnerships that support classroom teachers in designing game-based and mobile learning for interdisciplinary inquiry and civic engagement across school, online, and community settings.
\end{abstract}


A brisk morning with monochrome gray midwestern skies. 24 pre-service teachers leave their university classroom. Walking across campus, they carry personal mobile devices and maps, as well as concepts like the geometric properties of shapes and units of measurement. Divided into eight teams, pre-service teachers engage in a playful curricular module, their mobile investigation and interpretation concerning mathematics situated among familiar settings and circumstances. One team walks into a convenience store, surveys rows of beverages, and begins recording a video. Figure 1, below, is a screenshot of the moment when two pre-service teachers "discussed the prices of different water bottles of the same size. They discovered that by comparing the bottle's prices and sizes, they could find the cheapest" (m3.g3i2). Their investigation echoes research about supermarket arithmetic, and the dialectical relations of setting and activity that emerge when resolving the "problems" of shopping (Lave et al., 1984). This conversation about units, cost, and comparison illustrates the game-based activity's purpose - to playfully explore mathematics featured in the everyday activities of people and places, and to creatively represent this inquiry with digital media. This article describes the feasibility of designing and fostering pre-service teacher inquiry-as-play at the intersection of community and disciplinary engagement.

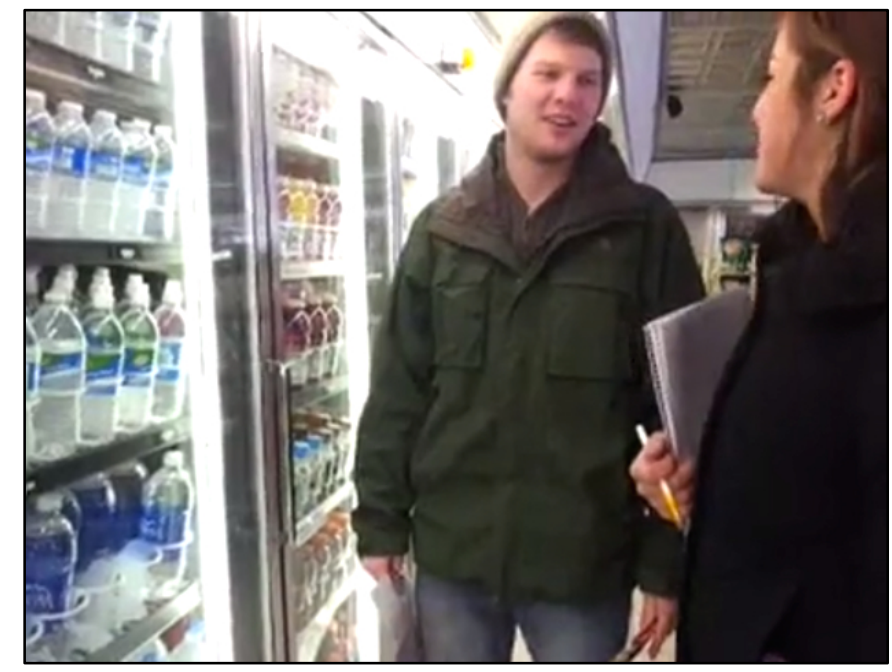

Figure 1. Screenshot of pre-service teachers comparing the price and volume of water

\section{Background: Disciplinary Inquiry Across Settings}

The mathematics future educators are often prepared to teach in school differs from the mathematical practices of everyday people, places, and cultures (Gutiérrez, 2010). Stevens (2013) describes this difference as "in-not-as;" the mathematics embodied in everyday social, cultural, and professional practices is distinguished from mathematics as activity, or the decontextualized problems and rote exercises of school study. Within teacher education, one response to this enduring fissure between school and everyday mathematics has been the design and use of digital technologies to connect disciplinary inquiry with real world scenarios, settings, and applications (e.g. Carmona et al., 2011; Roschelle et al., 2013). These developments have advanced complex and learner-centered approaches to mathematical inquiry; they have also modeled novel pedagogy for pre-service teachers. However, many of these experiences simulate everyday practices, privilege classrooms as the container for technology-rich mathematical 
inquiry (Klein, 2007), and seldom reflect the cultures of K-12 students from nondominant backgrounds (Khisty \& Willey, 2013). Technological and pedagogical innovation in mathematics teacher education often remains stuck inside university classrooms, disconnected from the people and places that comprise everyday mathematical knowledge and practice.

As the boundaries distinguishing formal from informal practice, and classroom from community engagement continue to blur (Kumpulainen \& Sefton-Green, 2014), disciplinary inquiry across settings is increasingly a concern of both university teacher educators (e.g. Gutiérrez \& Vossoughi, 2010; Jurow et al., 2012) and also K-12 mathematics educators (e.g. Turner et al., 2012; White \& Martin, 2014). In an attempt to better connect school with everyday mathematics, this study describes a game-based activity designed with an explicit assumption; it is possible to unsettle learning practices from schooling settings (Leander et al., 2010). More specifically, mathematics teacher education need not be entirely synonymous with a university or mathematics classroom (e.g. Aguirre et al., 2013). An unsettling of teacher education via crosssetting pedagogy and inquiry recalls Collins and Halverson's (2009) prediction reimagining the relationship between schooling and location. They suggest: "As learning moves out of school, our conception of learning will begin to broaden, and we will see more hybrid experiences that begin in the classroom and move into other contexts... emphasizing field trips, interacting with peers, playing computer games, or even teaching others with technological tools" (p. 129). If (mathematics) teacher education efforts are to facilitate hybrid experiences in either program design or pedagogy (Zeichner, 2010), then curricular modules like the one described in this study may serve as a design template for disciplinary inquiry that moves teacher preparation outside of the higher education classroom and across multiple community and online settings.

In K-12 and higher education contexts, the design and use of mobile and game-based learning activities has meaningfully supported disciplinary inquiry across settings (e.g. Holden et al., 2015; Squire, 2013). Whether these curricula and games concern park conservation or civic engagement, many - like the design featured in this study - are created according to a core set of principles. First, learning can be socially situated in conversation, coordinated in shared action, and embedded in specific circumstances (e.g. Lave and Wenger, 1991); such social relations shape how students-as-players participate in game-based activity and, hence, how they learn. Second, learning can also be situated among material and cultural relations, distributed across tools, physical objects, features of the environment, and cultural practices (e.g. Brown et al., 1989). Third, access to digital resources via mobile devices can mediate learners' interactions within and across settings via repertoires of disciplinary practices. Accordingly, discipline-specific inquiry can be designed beyond the four walls of a classroom, in neighborhoods, watersheds, town halls, and also within digital environments (Squire et al., 2007). White and colleagues (2011) assert, for example, that mobile learning across settings can bridge "gaps between formal and informal learning in mathematics" ( $p$. 11). Lastly, by adopting roles learners participate in experiences that authentically simulate problem solving and disciplinary investigation as practiced by professionals (e.g. Squire and Klopfer, 2007). These principles, intended to create the conditions for more equitable disciplinary inquiry across settings (i.e. Penuel et al., 2014), introduce Mapping My Math (MMM), a curricular module designed to guide pre-service teachers' mobile investigation and interpretation of everyday mathematics outside the classroom. This study addresses the 
following question: How can game-based and mobile learning be designed to support preservice teachers' disciplinary inquiry of everyday mathematics?

\section{Methods: Designing Mobile Inquiry Across Settings}

This study draws from design-based research (Cobb et al., 2003) that examined the role of place, digital media, and mobility in mathematics teacher education. The research occurred within a single mathematics methods course at a large state research university and utilizes data from three course iterations: Spring 2012 (M1); Fall 2012 (M2); and Spring 2013 (M3). I detail via design narrative (Bell et al., 2004) how MMM supported pre-service teachers' mobile investigation and interpretation of everyday mathematics. I treat the design of MMM "holistically," as "the intervention as enacted is a product of the context in which it is implemented, [and] the intervention is the outcome (or at least an outcome) in an important sense" (Design-Based Research Collective, 2003, p. 5). MMM was enacted within the context of what many teacher educators might recognize as a typical university-based methods course. The course was one of four elementary mathematics methods courses taught each semester in the teacher education program, with consistency among resources, assignments, and standards across sections. Week-to-week, pre-service teachers planned and facilitated lessons, practiced pedagogy, read and discussed literature, and completed group and individual projects. Supporting disciplinary inquiry across settings, particularly via game-based and mobile learning, was not a concern shared among the four course sections.

By describing contextual variables among which this design was created and enacted (Hoadley, 2002), this narrative describes how exploration outside the classroom-as-container via inquiryas-play situated pre-service teacher learning among contingent arrangements of everyday mathematics. The forthcoming narrative accounts for how MMM was designed, implemented, and refined to support such disciplinary inquiry across settings given the "evolution" of tools, activities, and practices characteristic of design research (Bell et al., 2004). Further, my design narrative echoes Barab and colleagues' (2009) "worked example" approach, whereby "it is the responsibility of the designer to purposively select particular data and to position these data and their contextual and critical framing such that collectively they both allow others to appreciate their theoretical importance and, at the same time, engage in their own framing of their meanings" (p. 4). My narrative frames MMM as intentionally encouraging pre-service teachers to playfully leverage disciplinary practices, thereby shaping new relationships with mathematics, their city, and the mathematics of place and community (Gutiérrez, 2010; Klein, 2007).

Given MMM's guiding design principles and methodological influences, what were the primary features of this game-based mobile learning activity? MMM featured situated roleplay. Each team of pre-service teachers included a player-as-geographer tasked with drawing representations of location and distance as the group walked from campus, through adjacent neighborhoods, and back to the classroom. A pre-service teacher also role-played as an ethnographer who observed social and material relations, and noted the mathematical qualities of team interactions. Another role played by pre-service teachers was of a media specialist; this individual collected data through photographs, audio, and video. Quests were another feature of MMM. MMM began with teams venturing about outside the classroom, exploring a range of disciplinary topics embedded in everyday circumstances, like greater and less than, 
inequality, and operations. Open-ended prompts helped scaffold disciplinary inquiry: How does mathematics include or exclude people from a place? How does mathematics enable or limit behavior? In what ways is mathematics an aesthetic or natural phenomenon? Like an open-ended sandbox game, MMM was designed as a "possibility space" (Squire, 2008) encouraging multiple trajectories of participation across settings and social relations.

MMM also supported pre-service teachers in interpreting disciplinary inquiry via media production. The creation of media representations is a common element in game-based and mobile learning (i.e. Mathews \& Holden, 2012; Peppler \& Kafai, 2010). After collecting mobile media, MMM featured pre-service teachers producing media to represent nascent understandings of school and everyday mathematics connections. Teams prototyped and created placemarks - or location-specific digital artifacts including descriptive text and embedded media - in Google My Maps as a meaning-making process (Taylor \& Hall, 2013). Pre-service teachers designed within teams and then collaborated among the cohort to produce interpretive maps of all quests. Pre-service teachers accomplished and represented via digital media 72 quests during M1, 49 in M2, and 92 during M3. Figure 2, below, is the M3 map; distinct colors and shapes indicate the affiliation of quest placemarks to teams.

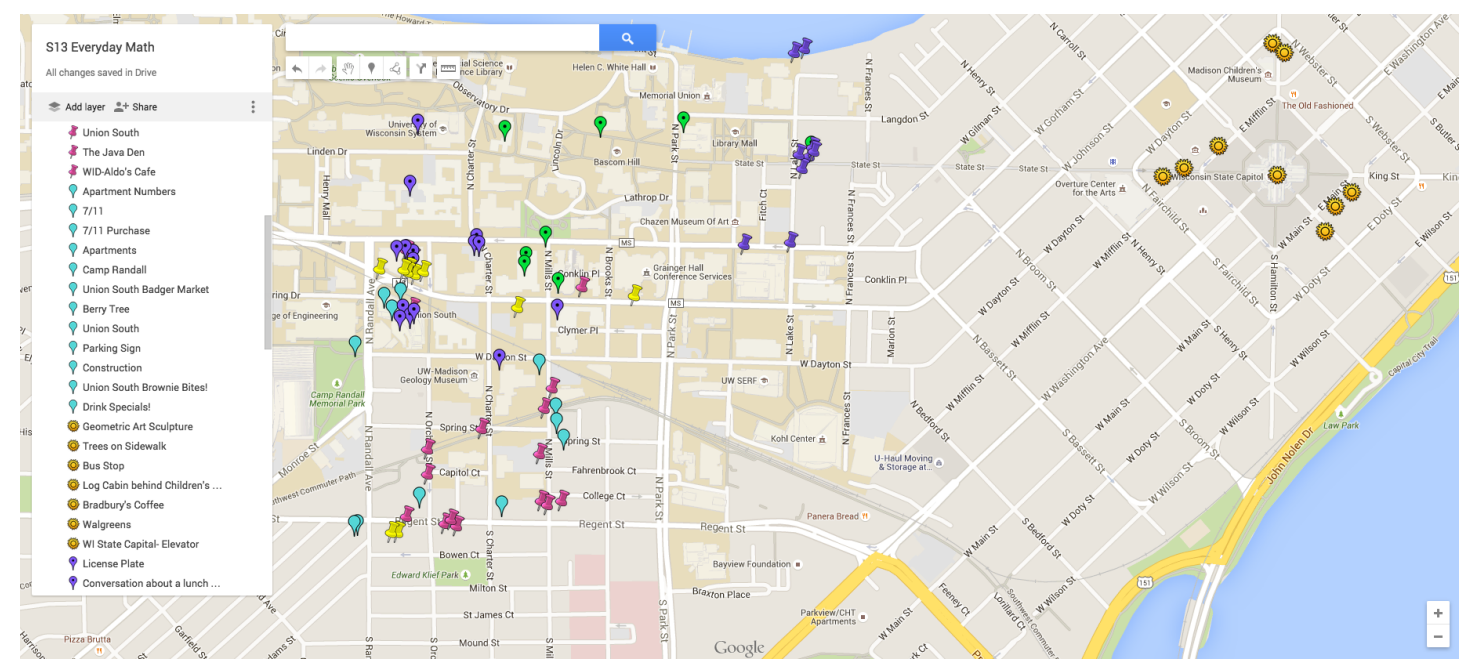

Figure 2. M3 map with mobile quest placemarks authored by pre-service teachers

To fully frame the intent of this worked example, it is important to recognize that MMM was not designed as a game, per se. Rather, MMM was a game-based mobile learning activity designed to encourage play, or "free movement within a more rigid structure" (Salen and Zimmerman, 2004, p. 304). MMM quests, for example, required that pre-service teacher inquiry attend to 14 disciplinary categories informed by the Common Core State Standards: Aesthetics, commerce, conversation, cooperation, development, exclusion and limits, greater and less than, history, inequality, interaction, law, nature, operations, and visual. Free movement, or mobility, occurred within a pre-determined conceptual structure. Play was also spatially demarcated, as teams physically traversed the sidewalks, bike paths, and campus buildings of a familiar cityscape. The free movements of mobile learning also arose in response to material and relational constraints, as pre-service teachers utilized everyday objects like mobile phones and everyday connections like online social networks. Figure 3 is a snapshot of pre-service teacher inquiry-as-play. 
Inquiry-as-play is defined as expressive mobility situated amongst learners' social and material relations, disciplinary concepts, and the built environment.

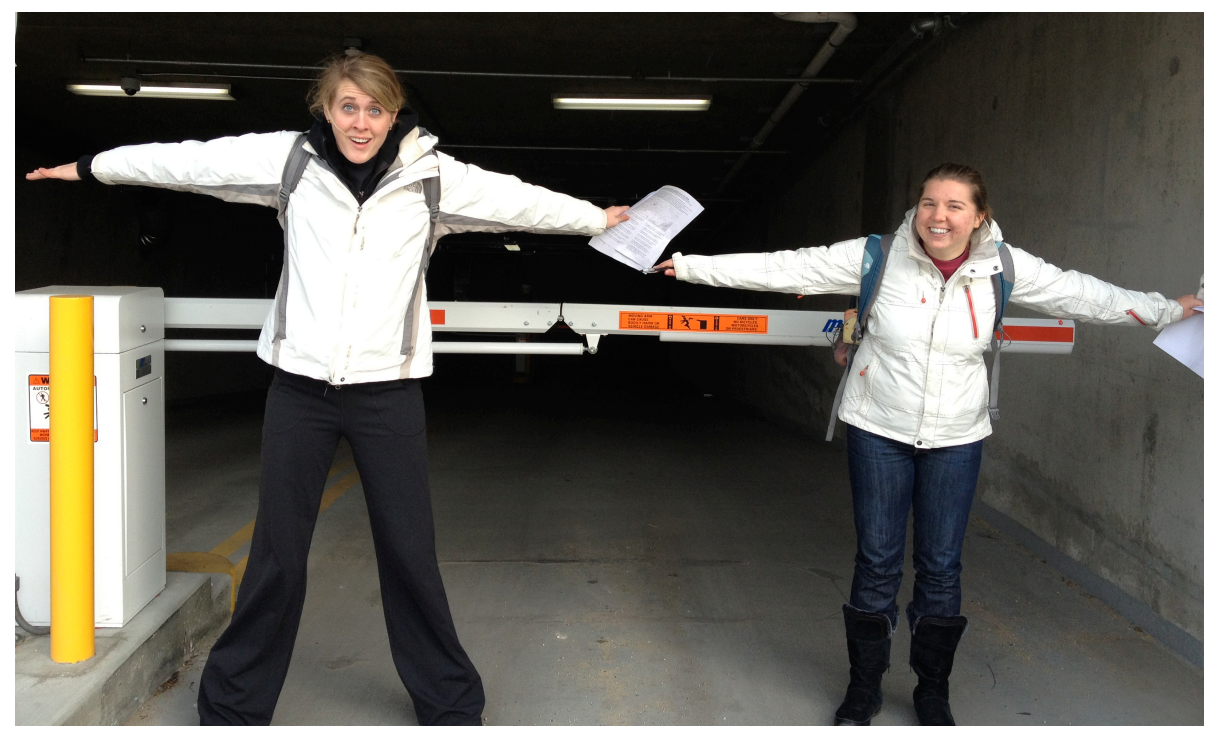

Figure 3. Pre-service teachers' "arm lift" during M1

For these pre-service teachers, standing at a parking garage entrance may have been improvisational. Their ongoing orchestration, however, was not imprudent. Entangled together was the social with the setting - the pairing of two people's arms lifted in parallel to the two "arms" of a gate - and also various material objects, including paper, pen, and the mobile phone that produced this image. So too were disciplinary concepts implicated in their activity. This configuration was an interpretation of law, or the use of mathematics in upholding and defining acceptable action. According to these pre-service teachers, playful inquiry about law was associated with the geometry of "an arm lift that had to raise and lower at an angle" ( $m$ 1.g2i5). The inquiry-as-play of "arm lift" was both object and action, both referent and embodiment in a coordinated representation of the disciplinary in the everyday. Just as disciplinary inquiry about the unknown relies upon established traditions and practices, so too does play require flexibility and expression within accepted parameters. The following design narrative describes the conditions and outcomes of inquiry-as-play within MMM given how "discipline" operated as both a noun and a verb. MMM encouraged pre-service teachers to move about familiar campus and city settings playfully, utilizing a distributed approach to disciplinary inquiry-as-play that complemented classroom-based teacher preparation.

\section{Design Narrative: Inquiry-as-Play in MMM}

My design narrative describes the "evolution" (Bell et al., 2004) of MMM during three iterations (M1, M2, M3). I examine pedagogical decisions and shortcomings associated with incorporating a game-based and mobile learning activity in mathematics teacher education. I also highlight indicators of pre-service teachers' disciplinary inquiry-as-play across settings.

The design of M1 made assumptions about how pre-service teachers would leverage mobile devices for inquiry-as-play outside the university classroom. When introducing MMM, my co- 
instructor and I failed to distinguish quotidian mobile device use from specialized disciplinary investigation; strategies for community engagement (i.e. interviewing) were not modeled, nor were pre-service teachers shown examples of everyday mathematics scenarios to investigate. We also neglected to discuss how a range of device functions - like using a camera for both photography and video - could document different concepts (i.e. shapes in architecture compared to rate in movement). In an effort to get pre-service teachers investigating outside the classroom, we quickly previewed the 14 quest categories. This might explain why some teams perceived quests less as opportunities for nuanced inquiry, and instead as the checklist of a timed scavenger hunt. Further, following community investigation little time was allotted to prototype media representations. Rather, instructions were posted to a course wiki (including a hyperlink to Google My Maps "Help") to support subsequent media authoring.

Collectively, it is likely that these limitations negatively influenced the quality of pre-service teachers' inquiry-as-play and media production. Connections established between everyday and school mathematics were superficial, as descriptive text from three quest placemarkers indicates:

- Development: "The crane that is being used to build the power plant uses angles and other mathematical concepts in order to be successfully operated" (m1.g3di5).

- Greater and Less Than: "Here we had a conversation with the cashier about how much coffee is, compared their price $(\$ 1.85)$ for a regular coffee to McDonald's $(\$ 1)$ and Greenbush (\$1.20)" (m1.g8i9).

- Visual: "The sign of the Art Museum uses shapes (circle, square, triangle) in its logo" (m1.g3di3).

Despite these shortcomings, many pre-service teachers reported that MMM was useful and novel: "I liked this activity because it got us up and moving - I learned a lot about the Madison community that I didn't know before that I think will help me in my practicum. Also helped me as a student to see math in everyday life and made me wonder how I can include activities like this in my own classroom" (m1.es 15). Another pre-service teacher remarked, "I felt so cliché thinking that math was everywhere, because that is what math teachers always say, but it was powerful to experience it for myself" (m1.es 14). Nonetheless, when my co-instructor and I evaluated M1 we concluded that enthusiasm with game-based activities actually detracted from in-depth disciplinary inquiry. While we were encouraged that pre-service teachers found MMM meaningful, we recognized obstacles associated with engendering purposeful inquiry-as-play.

The M2 redesign featured two improvements. First, we restructured the introduction. A Google Maps model illustrated everyday mathematics examples across the city, pre-service teachers discussed where and how they might investigate (i.e. identifying neighborhoods, planning routes via public transportation), mobile device features were demonstrated, and investigation strategies like interviewing and participant observation were introduced. Unlike M1, we emphasized the importance of careful and thoughtful investigation, and reminded pre-service teachers that they could identify multiple instances of a given quest. An unintended consequence of this detailed introduction, however, was pre-service teacher concern that game-based and mobile inquiry may be unrealistic given typical school constraints: "Should I assume that my students have access to technology? I am beginning to think about the community surrounding the schools that I want to teach at, and is it realistically plausible to do [such] learning in some areas that schools are located?" (m2.es18). The second change helped to scaffold media production. I recorded and 
shared video screencasts that identified the features of Google My Maps, explained how to upload and share media via cloud-based platforms, and reviewed online collaboration strategies.

These changes likely improved the quality of how pre-service teachers represented their inquiryas-play, as evidenced by descriptions of the following quests:

- Aesthetics: "On the map, the room numbers are in a sequence. There are various room shapes and sizes. The proportions of rooms are interesting, as is the circle room located at the main entrance off of Main Street and University Avenue. Question: We wonder, why did they chose to design the building this way? The circular areas of the building seem to be focal points" ( $m 2 . g 3 i 5)$.

- History: "When walking up to the $13^{\text {th }}$ Floor of the Education Building our group noticed a timeline on the wall that described a Historical Timeline for the School of Education. In $2^{\text {nd }}$ grade students are to learn how to 'compare and order whole numbers' and 'determine relationships of numbers 1-1000.' Using a number line student will be able to look at relationships to events that have happened in history and compare their relationships based on the size of the year" $(m 2 . g 7 i 1)$.

Like M1, many pre-service teachers found MMM relevant to other teacher education activities, such as practicum teaching. One pre-service teacher commented: "I am beginning to think about specifically what in the community around my practicum school that my practicum students might want to investigate mathematically. In relation to this place-based approach I am thinking about how to meet standards while allowing students the freedom to navigate their own learning" (m2.es 11). A critical assessment of M2, however, also revealed recurrent obstacles, such as developing and encouraging the media production skills of all pre-service teachers, and connecting quality media representations with conceptual insights from disciplinary inquiry.

The final iteration, M3, built upon the previous M2 revisions through two complementary improvements. First, pre-service teachers facilitated a post-community investigation discussion. The conversation examined connections between MMM and pre-service teachers' previous experiences with place-based learning. This was a useful reflection, as multiple pre-service teachers shared observations such as: "Much of the learning was student-led, as we made connections between the outside world and math, such as the student-led discussion" (m3.es4). A second change supported digital media production. I hosted two "design jams" during consecutive weeks, for two hours in the evening, and at a central campus location. Pre-service teachers from half the teams attended either design jam. At these jams, pre-service teachers accessed media production resources, asked technical design questions, and worked collaboratively to create placemark representations. The design jams offered a semi-structured opportunity to work in the presence of more skilled peers, mitigating some obstacles associated with pre-service teachers' media authoring competencies.

M3 refinements likely influenced the caliber of pre-service teachers' inquiry-as-play and media production, as glimpsed via representative descriptions of everyday mathematics:

- Exclusion and Limits: "The stoplight here has turned yellow, and the timer shows zero seconds. This limits people from crossing for safety reasons. Does the number of people who cross the street correlate with the amount of time there is to cross?" (m3.g7i2). 
- Inequality: "The handicap parking sign demonstrates that certain people have privileges over others. In this case people with a handicap have a special privilege, but there are similar signs that give access to those who have the power to purchase a parking spot, professors, and more. It has to do with math because the spot offers a closer proximity to the main entrance than other spots in the lot" (m3.g5i5).

Echoing responses from M1 and M2, pre-service teachers' post-activity reflections indicated a desire "to create and incorporate certain mathematics concepts into my students' community and learn of mathematics in their everyday lives" (m3.es5). Yet at the conclusion of M3, we confronted a proof-of-concept dilemma not atypical of design-based research (Brown, 1992). While game-based and mobile learning may not be a priority for mathematics teacher educators in other contexts, supporting pre-service teacher inquiry-as-play usefully connected classroom with community engagement, as well as school with everyday mathematics.

\section{Discussion: Techniques and Implications for Inquiry-as-Play}

MMM utilized game-based and mobile learning to support pre-service teacher inquiry of mathematics outside the university classroom, and leveraged digital media to represent connections between school and everyday mathematics. This discussion considers techniques and implications for designing and enacting inquiry-as-play in mathematics teacher education.

Given the exploratory nature of this research, insights gleaned from this design narrative should be considered provisional and subject to further systemic inquiry. Nonetheless, assessing three MMM iterations reveals various "design techniques" useful for "escaping a particular kind of pitfall or for addressing a particular kind of design challenge" (Hoadley \& Cox, 2009, p. 28). The following techniques may be relevant to other game-based and mobile learning researchers designing in the field of (mathematics) teacher education. First, the enactment of MMM suggests pre-service teachers may not have prior experience identifying disciplinary concepts and practices outside of school (e.g. Aguirre et al., 2013). Accordingly, it was useful to model mobile investigation and interpretation strategies. Second, despite these learners' familiarity with mobile devices, using this technology during inquiry-as-play required demonstrating how to capture and collect media, and also how to interview people and observe phenomena in situ (e.g. Mathews, 2010). Third, out-of-classroom inquiry was complemented by constructivist pedagogy, such as learner-centered discussion and small-group collaboration (i.e. design jams). Fourth, despite observations about Millennials' digital and mobile media savvy (e.g. Ito et al., 2010), technical and pedagogical design scaffolds were necessary for learners to creatively represent community-based inquiry. The utility of these design techniques echo observations about the supports "digitally able" novice educators require when integrating technology into their teaching (Starkey, 2010), indicating future research might examine how pre-service teachers leverage everyday digital and mobile practices as professional learning resources.

By demonstrating how game-based and mobile learning may be enacted to support pre-service teachers' disciplinary inquiry of everyday mathematics, this study advances varied implications for similar designs in mathematics teacher education. First, this design narrative suggests that mobile learning in mathematics teacher education has the potential to "awaken the connections among home, school, and community and give [pre-service teachers] a forum to generate their 
own personal and mathematical development" (White et al., 2011, p. 11). The personal and professional qualities of such development are apparent in one pre-service teacher's reflection: "I am thinking about the role of the community, a question that I still have is, do teachers need to live in the community in which they teach?" (m2.es 15). Second, MMM turned a university campus and its surrounding neighborhoods into a game board (i.e. Squire, 2011). In doing so, MMM exploited how "a city can be gameful, or perhaps more precisely how gameful design can enable people to shape urban environments in various ways" (Alfrink, 2014, p. 529). The gameful design of MMM enabled pre-service teachers to shape disciplinary relations across community, classroom, and online environments, as well as the pedagogical dimensions of another - the local schools in which they were teaching. As one remarked after participating in MMM: "I am supposed to be teaching a lesson this upcoming week, and this class got me to reflect and look forward to constructing my lesson plan, and how I can/could incorporate placebased learning and relevant material to my class of $8^{\text {th }}$ graders" (m2.es19).

Finally, the inquiry-as-play evidenced during MMM recalls the importance of "boundary crossing" activities (e.g. Akkerman \& Bakker, 2011), whereby learners come to see the familiar in new ways, and also act in new ways among familiar settings. MMM established gameful conditions for "boundary crossing" within mathematics teacher education. Pre-service teachers moved among campus and community locations, collaborated socially, investigated and interpreted disciplinary concepts in everyday circumstances, and utilized mobile and online technologies to mediate these experiences. The impact of such inquiry-as-play recalls one preservice teacher's comment about "allowing students the freedom to navigate their own learning." MMM afforded pre-service teachers the freedom to play and navigate their own learning within disciplinary and everyday structures. In doing so, MMM created the conditions for cross-setting mobility - of people across places, of information and media across networks, of concepts across contexts - as generative of opportunities for inquiry-as-play in mathematics teacher education.

\section{References}

Aguirre, J. M., Turner, E. E., Bartell, T. G., Kalinec-Craig, C., Foote, M. Q., Roth McDuffie, A., \& Drake, C. (2013). Making connections in practice: How prospective elementary teachers connect to children's mathematical thinking and community funds of knowledge in mathematics instruction. Journal of Teacher Education, 64(2), 178-192.

Alfrink, K. (2014). The gameful city. In S. Walz \& S. Deterding (Eds.), The gameful world: Approaches, issues, applications (pp. 527-560). Cambridge, MA: MIT Press.

Akkerman, S., and A. Bakker. 2011. Boundary crossing and boundary objects. Review of Educational Research, 82(4), 132-69.

Barab, S., Dodge, T., \& Gee, J.P. (2009). The worked example: Invitational scholarship in service of an emerging field. Paper presented at the annual meeting of the American Education Research Association, San Diego, CA.

Bell, P., Hoadley, C.M., \& Linn, M.C., (2004). Design-based research in education. In Linn, M.C., Davis, E.A., \& Bell, P. (Eds.), Internet environments for science education (pp. 73-85). Lawrence Erlbaum Associates. 
Brown, A. L. (1992). Design experiments: Theoretical and methodological challenges in creating complex interventions in classroom settings. The Journal of the Learning Sciences, 2(2), 141-178.

Brown, J. S., Collins, A., \& Duguid, P. (1989). Situated cognition and the culture of learning. Educational Researcher, 18(1), 32-42.

Carmona, G., Domínguez, A., Krause, G., \& Durán, P. (2011). Emergent public spaces: Generative activities on function interpolation. Contemporary Issues in Technology and Teacher Education, 11(4), 362-381.

Cobb, P., Confrey, J., diSessa, A., Lehrer, R., \& Schauble, L. (2003). Design experiments in educational research. Educational Researcher, 32(1), 9-13.

Collins, A., \& Halverson, R. (2009). Rethinking education in the age of technology: The digital revolution and schooling in America. New York, NY: Teachers College Press.

Design-based Research Collective. (2003). Design-based research: An emerging paradigm for educational inquiry. Educational Researcher, 32(1), 5-8.

Gutiérrez, K. D., \& Vossoughi, S. (2010). Lifting off the ground to return anew: Mediated praxis, transformative learning, and social design experiments. Journal of Teacher Education, 61(1-2), 100-117.

Gutiérrez, R. (2010). The Sociopolitical Turn in Mathematics Education. Journal for Research in Mathematics Education, 41(0), 1-32.

Hoadley, C. P. (2002). Creating context: Design-based research in creating and understanding CSCL. In Proceedings of the Conference on Computer Support for Collaborative Learning: Foundations for a CSCL Community (pp. 453-462). International Society of the Learning Sciences.

Hoadley, C., \& Cox, C. D. (2009). What is design knowledge and how do we teach it? In C. DiGiano, S. Goldman, \& M. Chorost (Eds.), Educating learning technology designers: Guiding and inspiring creators of innovative educational tools, (pp. 19-35). New York, NY: Routledge.

Holden, C., Dikkers, S., Martin, J., \& Litts, B. (Eds.). (2015). Mobile media learning: Innovation and inspiration. Pittsburgh, PA: ETC Press.

Ito, M., Baumer, S., Bittanti, M., Boyd, D., Cody, R., \& Herr-Stephenson, B. (2010). Hanging out, messing around and geeking out: Kids living and learning with new media. Cambridge, MA: The MIT Press.

Jurow, A. S., Tracy, R., Hotchkiss, J. S., \& Kirshner, B. (2012). Designing for the future: How the learning sciences can inform the trajectories of preservice teachers. Journal of Teacher Education, 63(2), 147-160.

Khisty, L. L., \& Willey, C. J. (2013). After-school: An innovative model to better understand the mathematics learning of Latinas/os. In B. Bevan, P. Bell, R. Stevens, \& A. Razfar (Eds.), LOST opportunities: Learning in out-of-school time (pp. 233-249). New York, NY: Springer.

Klein, R. (2007). Educating in place: Mathematics and technology. Working Paper No. 38. Appalachian Collaborative Center for Learning, Assessment, and Instruction in Mathematics (ACCLAIM).

Kumpulainen, K. \& Sefton-Green, J. (2014). What is connected learning and how to research it? International Journal of Learning and Media, 4(2), 7-18.

Lave, J. \& Wenger, E. (1991). Situated Learning: Legitimate Peripheral Participation. Cambridge, UK: Cambridge University Press. 
Lave, J., Murtagh, M., \& de la Rocha, O. (1984). In B. Rogoff \& J. Lave (Eds.), Everyday cognition: Its development in social contest (pp. 67-94). New York, NY: Cambridge University Press.

Leander, K.M., Phillips, N.C., \& Taylor, K.H. (2010). The changing social spaces of learning: Mapping new mobilities. Review of Research in Education, 34(1), 329-394.

Mathews, J. (2010). Using a studio-based pedagogy to engage students in the design of mobilebased media. English Teaching: Practice and Critique, 9(1), 87-102.

Mathews, J., \& Holden, J. (2012). Place-based design education: A pedagogy for classroom and community-based civic participation. In S. Dikkers, J. Martin, \& B. Coulter (Eds.), Mobile media learning: Amazing uses of mobile devices for teaching and learning, (pp. 131-148). Pittsburgh, PA: ETC Press.

Penuel, W. R., Lee, T., \& Bevan, B. (2014). Designing and building infrastructures to support equitable STEM learning across settings. Cambridge, MA: Research and Practice Collaboratory.

Peppler, K. \& Kafai, Y. B. (2010). Gaming fluencies: Pathways into a participatory culture in a community design studio. International Journal of Learning and Media, 1(4), pp. 1-14.

Roschelle, J., Courey, S., Patton, C., \& Murray, E. (2013). Dynabooks: Supporting teachers to engage all learners in key literacies. In C. Mouza \& N. Lavigne (Eds.), Emerging technologies for the classroom: A learning sciences perspective (pp. 31-46). New York, NY: Springer.

Salen, K., \& Zimmerman, E. (2004). Rules of play: Game design fundamentals. Cambridge, MA: MIT press.

Squire, K. (2008). Open-ended video games: A model for developing learning for the interactive age. In K. Salen (Ed.), The ecology of games: Connecting youth, games, and learning (pp. 167-198). Cambridge, MA: MIT Press.

Squire, K. (2011). Video games and learning: Teaching and participatory culture in the digital age. New York, NY: Teachers College Press.

Squire, K. (2013). Mobile media learning: Ubiquitous computing environments for the mobile generation. In C. Mouza \& N. Lavigne (Eds.), Emerging technologies for the classroom: A learning sciences perspective (pp. 187-204). New York, NY: Springer.

Squire, K., \& Klopfer, E. (2007). Augmented reality simulations on handheld computers. Journal of the Learning Sciences, 16(3), 371-413.

Squire, K., Jan, M., Mathews, J., Wagler, M., Martin, J., DeVane, B., \& Holden, C. (2007). Wherever you go, there you are: Place-based augmented reality games for learning. In B. Shelton, \& D. Wiley (Eds.), The educational design and use of simulation computer games, (pp. 275-296). Rotterdam, The Netherlands: Sense Publishers.

Starkey, L. (2010). Supporting the digitally able beginning teacher. Teaching and Teacher Education, 26(7), 1429-1438.

Stevens, R. (2013). What counts too much and too little as math. In B. Bevan, P. Bell, R. Stevens, \& A. Razfar (Eds.), LOST opportunities: Learning in out-of-school time (pp. 65-83). New York, NY: Springer.

Taylor, K. H., \& Hall, R. (2013). Counter-mapping the neighborhood on bicycles: Mobilizing youth to reimagine the city. Technology, Knowledge and Learning, 18(1-2), 65-93.

Turner, E. E., Drake, C., McDuffie, A. R., Aguirre, J., Bartell, T. G., \& Foote, M. Q. (2012). Promoting equity in mathematics teacher preparation: A framework for advancing teacher 
learning of children's multiple mathematics knowledge bases. Journal of Mathematics Teacher Education, 15(1), 67-82.

White, T., \& Martin, L. (2014). Mathematics and mobile learning. TechTrends, 58(1), 64-70.

White, T., Booker, A., Ching, C. C., \& Martin, L. (2011). Integrating digital and mathematical practices across contexts: A manifesto for mobile learning. International Journal of Learning, 3(3), 7-13.

Zeichner, K. (2010). Rethinking the connections between campus courses and field experiences in college-and university-based teacher education. Journal of Teacher Education, 61(1-2), 89-99. 